\title{
FRAGMENTACIÓN Y BIFURCACIÓN EN EL SISTEMA INTERNACIONAL POS COVID-19: LAS IMPLICACIONES PARA CENTROAMÉRICA
}

\author{
FRAGMENTATION AND BIFURCATION IN THE POST \\ COVID-19 INTERNATIONAL SYSTEM: IMPLICATIONS \\ FOR CENTRAL AMERICA ${ }^{1}$
}

\section{Alexander López Ramírez²}

ORCID: 0000-0002-3700-6161

\section{Luis Diego Segura Ramírez ${ }^{3}$ \\ ORCID: 0000-0002-5278-7699}

\section{RESUMEN}

La época contemporánea se caracteriza por dos rasgos que la determinan: la fragmentación de la gestión del sistema internacional y la bifurcación de alternativas representada por los actores centrales del sistema. Esto explica las tensiones entre China y Estados Unidos, la ausencia de un administrador del sistema global (actor hegemónico) y la emergencia de poderes intermedios que han adquirido mayor visibilidad en el contexto de la pandemia. Este nuevo contexto sistemático se presenta en la región centroamericana como un actual reto estratégico, por cuanto esta ha adquirido mayor preponderancia como zona de influencia, pero, a su vez, se denota una fragmentación creciente a lo interno de sus países, la potencialidad de la cooperación y el conflicto crean importantes oportunidades, pero también amenazas que deben ser atendidas

\section{ABSTRACT}

The contemporary era is characterized by two attributes that determine it: fragmentation in the management of the international system and bifurcation of alternatives represented by key actors of the system. These phenomena explain the tensions between China and the United States, the absence of a global system administrator (hegemonic actor), and the emergence of intermediate powers that have gained greater visibility in the context of the pandemic. This new systematic context is presented in the Central American region as a new strategic challenge, since it has acquired greater preponderance as a zone of influence, but at the same time there is a growing fragmentation within its countries, the potential for cooperation and conflict creates important opportunities but

1 Una versión inicial del presente artículo fue difundida como un artículo de discusión a mediados de 2020 como parte del documento "Escenarios en un mundo transformado: cinco tesis sobre el futuro del sistema internacional" publicada por el Instituto Centroamericano de Administración Pública (ICAP). La que se presenta aquí la actualiza y profundiza; además, integra una sección sobre cómo el fenómeno estudiado afecta a la región centroamericana en el marco de la conmemoración del bicentenario de independencia.

2 Universidad Nacional. Profesor de la Escuela de Relaciones Internacionales. Ph.D. por la Universidad de Oslo, Noruega. Correo electrónico: alexander.lopez.ramirez@una.cr

3 Universidad Nacional. Profesor de la Escuela de Relaciones Internacionales. Ph.D. candidate por la Universidad de Maastricht, Países Bajos. Correo electrónico: luis.segura.ramirez@una.cr 
oportunamente si se desea evitar los errores del pasado.

Palabras clave: Bifurcación; Centroamérica; China; Estados Unidos; fragmentación; Sistema internacional also threats that must be addressed in a timely manner to avoid past mistakes.

Key words: Bifurcation; Central America; China; fragmentation, international system; United States

\section{Introducción}

Antes de sintetizar las tesis centrales que permiten establecer una relación coherente $\mathrm{y}$, a partir de las cuales se fundamenta este estudio, conviene describir las coordenadas históricas existentes en el mundo prepandemia, en particular, aquellas que se han trastocado entre 2020 y lo que va del año 2021, de un modo tan radical y definitivo, que se ha originado un acelerado proceso de transición global, un cambio de época. A grandes rasgos, puede afirmarse que, entre los años 1980 y 2019 el sistema internacional experimentó cuatro cambios fundamentales: Primero: la desaparición de sistemas sociales, económicos y políticos de naturaleza centralista y monolítica que en Europa fueron conocidos como de "socialismo real". Este fenómeno, que en lo fundamental tuvo como eje articulador la experiencia europea entre los años 1980 y 1990, fue liderado por los Estados Unidos e implicó la extinción de la Unión Soviética, del Pacto de Varsovia y del Consejo de Ayuda Mutua Económica, al tiempo que se relanzaban: las economías de mercado, los liberalismos económicos y políticos, se renovaba y profundizaba el proyecto de la Unión Europea y los Estados Unidos alcanzaban un poder global sin competidor alguno.

Sin embargo, nótese que el mencionado proceso transformador, no involucró cambios sustanciales en la República Popular China (RPCH) y este es un hecho, cuyas consecuencias ahora se observan en el ascenso económico y social de este país.

Segundo: se consolidó una economía planetaria que tomó como base las economías de mercado y la Tercera Revolución Industrial (digital), que evolucionó hasta el inicio de la Cuarta Revolución Industrial (4.0) que se convierte en un fenómeno, dentro del cual se sitúa la actual revolución científico-tecnológica y sus impactos en materia de productividad y competitividad de los sistemas económicos.

La Cuarta Revolución Industrial desintegra las fronteras entre las esferas físicas, digital y biológica de los sistemas sociales, e implica la emergencia, consolidación y desarrollo de la computación cuántica, la biotecnología, la 
nanotecnología, la inteligencia artificial, la robótica y el internet de las cosas, lo que lleva a la creación de clústeres en ámbitos como tecnologías de información, electrónica, mecatrónica, logística, salud, diseño, sostenibilidad, aeroespacial, oleo-química, energías renovables y audio visual, entre otros.

Tercero: como resultado de la revolución tecnológica, se creó una red de información global que ha impactado en las dinámicas educativas, culturales, políticas y económicas. Desde 1990, pero, sobre todo, a finales de la primera década del siglo XXI, quedó claro que la sociedad global se encaminaba hacia interacciones más automatizadas, electrónicas y virtuales; en consecuencia, la Economía Digital había llegado para quedarse en las estructuras permanentes del sistema internacional.

Cuarto: los cambios fácticos referidos se acompañaron de transformaciones paradigmáticas en las formas y contenidos del pensar, así como en las gestiones organizacionales. De modo que se puede afirmar que nació, se consolidó y se desarrolló el pensamiento complejo, disruptivo y propositivo; es decir, un nuevo paradigma que conlleva la generación de conocimientos multidisciplinarios, transdisciplinarios, interdisciplinarios y multireferenciales, socialmente disponibles, los cuales, permiten conocer e interpretar la realidad como una red global compleja de informaciones, de datos, de prácticas y de saberes. Todas estas transformaciones, en conjunto, implicaron un cambio de época en la década de los ochenta del siglo XX que impulsaron las dinámicas internacionales, desde entonces y hasta el año 2019. En consecuencia, el mundo en las primeras dos décadas del siglo XXI experimentó, por un lado, una profundización sin precedentes del fenómeno globalizador y de la revolución científico-tecnológica y, por otro lado, supuso varias situaciones económicas críticas, entre las que destaca la primera crisis económica global del siglo iniciada en el año 2008.

Los contornos estructurales de la sociedad global, durante este periodo, fueron determinados por la digitalización, el control global de la información, la intensificación de la Cuarta Revolución Industrial, la expansión de las redes sociales electrónicas, la masificación de los dispositivos móviles, el acceso universal a internet y, en general, el impulso a la conectividad como experiencia internacional. Todo en un sistema internacional que, con frecuencia, mostraba un conjunto de contradicciones políticas, ideológicas y militares entre imperios (EE. UU., China, Rusia) que no dejaban de subir en tensión y complejidad.

Así las cosas y, poco antes de declararse la pandemia del COVID-19, en el sistema internacional, se hablaba con claridad de la posibilidad de nuevas crisis económicas con sus correspondientes ramificaciones políticas, sociales y culturales. La pandemia y la política pública dominante para contrarrestarla han 
supuesto la aceleración de los factores que indicaban, en el 2019, la inminencia de una nueva recesión del sistema productivo y financiero con sus efectos más notorios: la conmoción social, la crisis política y la fragmentación de la gestión del orden global. De manera que, lo que empezó siendo un cambio de época (1980-1990), que condujo a una evolución positiva en muchos aspectos, ha concluido en una crisis sistémica internacional caracterizada por la combinación de cinco crisis: sanitaria, social, ambiental, política y de gestión de las interacciones sociales en el marco de la globalización.

Lo que hoy se llama la nueva "guerra fría" escenificada por EE. UU. y China $\mathrm{y}$, secundada por Rusia, la Unión Europea y algunos poderes emergentes es un fenómeno derivado de la crisis sistémica internacional, la cual, constituye el núcleo articulador del período de transición histórica que se está viviendo. En este marco transitivo deben ubicarse los contenidos de este artículo, que busca saber dónde se está, cómo se ha llegado hasta ese lugar, hacia dónde debe irse y, a través de que caminos conviene transitar, en especial cuando se aprecian estos fenómenos desde la pequeña y vulnerable región de Centroamérica.

\section{De la bipolaridad a la fragmentación del sistema internacional}

La Segunda Guerra Mundial (SGM) trajo consigo una reingeniería del sistema internacional. La fundación de la Organización de las Naciones Unidas (ONU) y el acuerdo de Bretton Woods permitieron crear un conjunto de instituciones que sentaron las bases del multilateralismo y del sistema económico de posguerra articulado en torno a los Estados Unidos como gran potencia mundial y líder de occidente.

El sistema internacional actual se ha regido sobre la base de un conjunto de instituciones heredadas de la paz de Westfalia como lo son la preponderancia del Estado como el principal actor, la soberanía del mismo como base de su capacidad de autodeterminación y la abstinencia de atentar contra la de los otros actores. Desde esta perspectiva, el sistema internacional es por naturaleza anárquico, con lo cual el balance de poder y el equilibrio entre las potencias es un aspecto fundamental que definen el conflicto y la cooperación (Waltz, 1988).

Con el final de la SGM esos elementos básicos se vieron afectados al crearse un conjunto de instituciones como la ONU y en especial el Consejo de Seguridad, así como un régimen de libre comercio y un conjunto de instituciones financieras del Sistema de Bretton Woods que son el Banco Mundial, el Fondo Monetario Internacional y el Acuerdo General de Aranceles y Comercio (denominado 
GATT en inglés), predecesor de la actual Organización Mundial del Comercio $(\mathrm{OMC})$.

Si bien las organizaciones mencionadas no han cambiado la naturaleza anárquica del sistema, sí es claro que han creado un conjunto de reglas que han venido a limitar el efecto que la anarquía tiene sobre los Estados, lo que ha generado importantes incentivos para la cooperación internacional en múltiples ámbitos, así como mecanismos para gestionar los conflictos al reducir el riesgo de enfrentamientos bélicos entre Estados. Esto es lo que ha determinado que el sistema internacional sea anárquico pero institucionalizado (Keohane, 1989) .

El final de la Guerra Fría favoreció la presunción de que esta institucionalidad, reforzada con el rol hegemónico de Estados Unidos, se convertiría en la estructura incuestionable del sistema internacional. Estos cambios llevaron a Francis Fukuyama (1989) a cuestionarse si estábamos ante el fin de la historia debido a la imposición del sistema occidental de libre mercado y democracia liberal como el incuestionable sistema ideológico e institucional global. Esto, basado en la incapacidad de cualquier alternativa (llámese comunismo o fascismo) de acuerpar un conjunto de actores preponderantes en el sistema internacional, con capacidad para competir con el sistema ideológico occidental.

Sin embargo, dicho "fin de la historia" parece ahora lejano debido a la creciente influencia del "modelo de desarrollo chino", el cuál si bien se alinea económicamente con el modelo liberal occidental no lo hace así en cuanto a su componente político. Además, desde la invasión unilateral de Estados Unidos a Irak en 2003 y la crisis económica de 2008 ha quedado cuestionada la estructura del sistema, sobre todo a partir del retraimiento de Estados Unidos en su rol de liderazgo global, reforzado, en especial, con la administración de Trump y la rápida y desorganizada retirada de Afganistán y su caída en manos del Talibán. Durante la gestión de Trump se produjo la salida de EE. UU. de importantes instituciones como el Acuerdo de París sobre Cambio Climático, la Alianza Transpacífico y, posterior rechazo del Acuerdo de Libre Comercio de América del Norte (NAFTA), se llevaron a cabo acciones limitadoras del rol de la OMC y también hubo accionar en contra de la Organización Mundial de la Salud (OMS) al retirar todo su financiamiento, bajo el argumento de que dicha organización sirve a los intereses de China y no actuó de forma responsable en la gestión de la crisis del COVID-19.

Si bien en varios de estos aspectos la nueva administración de Biden ha venido a corregir dicho accionar y a relanzar la imagen de que Estados Unidos está de vuelta en el escenario internacional, también es claro que ese "regreso" implica ajustes y acomodamientos importantes como el ya señalado de Afganistán. 
Además, la nueva alianza AUKUS (Australia-United Kingdom-United States, por sus siglas en inglés) que implica un importante giro en materia de desarrollo y cooperación de tecnología de submarinos nucleares, pero con detrimento de los intereses de Francia y su consecuente crisis diplomática, y con un claro objetivo de balancear el creciente poderío naval chino en el Pacífico al fortalecer el "cerco" a China.

Ahora bien, la crisis financiera de 2008 y la actual crisis producto del COVID-19 han servido como plataformas para presentar al modelo chino como un éxito a seguir, especialmente en los países en desarrollo. Esto en momentos donde tanto en Estados Unidos como en los mismos países europeos hay un creciente cuestionamiento al sistema internacional pos Segunda Guerra Mundial derivado de un nuevo nacionalismo en auge, y de liderazgos autoritarios que cuestionan los principios básicos de la democracia liberal (división de poderes, controles y balances), así como el libre comercio y el rol de la OMC para gestionar el régimen de comercio mundial. Es decir, a la vez que hay un declive en la importancia del modelo liberal occidental, hay un incremento en la importancia e influencia de nuevos centros de poder que no responden a dicho modelo.

Previo a la crisis derivada de la actual pandemia múltiples académicos han planteado que el sistema internacional heredado de la posguerra se encuentra en un franco proceso de transformación producto de profundos cambios como la creciente globalización e interdependencia que ha reducido la capacidad del Estado, aunado a una redefinición y reducción de su soberanía en beneficio de nuevos actores transnacionales (H. L. G. Brands, John, 2021; Kissinger, 2014; Murillo Zamora, 2018; Rosenau, 2007). Además, un nuevo equilibrio de fuerzas entre potencias emergentes, destaca, sobre todo, China y el repliegue de Estados Unidos en su rol de liderazgo global.

Este estado de situación pareciera generar tres grandes tendencias en el sistema internacional posCOVID-19. En primer lugar, el mundo se encuentra en un momento de bifurcación aguda por la creciente competencia entre Los Estados Unidos y China, inclusive hay un debate abierto sobre la posibilidad de una segunda guerra fría (Dupont, 2020; The Economist, 2020a; Wintour, 2020). En segundo lugar, esa bifurcación está generando que no exista un administrador del sistema o que no exista un acuerdo de administración del sistema entre las potencias; y finalmente, esta situación de fragmentación y bifurcación está provocando un mayor protagonismo de los denominados poderes intermedios. 


\section{Cooperación y conflicto internacional como resultado de la pandemia}

El COVID-19 ha venido a reforzar una primera reacción básica y cuasi fundamental en un sistema anárquico y sin un claro líder o administrador, prácticamente cada Estado velará por su propia sobrevivencia reduciendo así la probabilidad de cooperación en el sistema. Dicha reacción quedó patente cuando hacia finales de febrero e inicios de marzo de 2020 Italia se vio sola haciendo frente a la pandemia y países europeos socios como Alemania o Francia, lejos de cooperar decidieron adoptar restricciones al comercio de suplementos médicos básicos. Este tipo de medidas fueron adoptadas por múltiples países que incluyen a Estados Unidos, India, entre otros.

Esta misma característica, típica de un sistema anárquico, se está reflejando en los esfuerzos para crear y distribuir la vacuna contra dicho virus, con iniciativas de países como Estados Unidos, al solicitar a sus empresas farmacéuticas la priorización del mercado interno. Inclusive, países como el Reino Unido rechazaron unirse al llamado de la OMS de conformar una alianza para asegurar la libre transferencia de una eventual vacuna en el nivel global.

La concentración de vacunas en los países ricos ha demostrado esa incapacidad donde el mecanismo COVAX de la OMS no ha recibido suficientes vacunas $y$, por ende, el acceso de la vacuna ha sido muy limitado, favoreciendo inclusive una mayor propagación del virus y de nuevas mutaciones que acentúan el peligro de que los nocivos efectos de la pandemia se extiendan por más años.

La actual crisis está igualmente provocando lo que podría denominarse una securitización del COVID-19. Pasó de ser una amenaza a la salud a convertirse en una amenaza existencial al Estado, en el sentido que el objeto de referencia ya no es solo la salud humana, en general, sino el Estado como unidad del sistema. En este sentido, las medidas adoptadas como frenar el transporte internacional desde zonas contagiadas (por ejemplo, la prohibición de vuelos a China o Europa aprobada por el gobierno de Estados Unidos en su momento), la limitación del comercio internacional de suplementos médicos, la competencia por obtener una vacuna, entre otros mandatos, son claros ejemplos de este proceso de securitización.

La respuesta inicial, si bien marca un regreso al pasado, donde ante una amenaza existencial cada Estado actúa en función de sus propios intereses sin tener en cuenta a los demás, la naturaleza misma de la amenaza, al ser de carácter transnacional, requiere de un esfuerzo coordinado entre los Estados, pero también 
de estos con otros actores no estatales como empresas, redes de investigación, sociedad civil y, desde luego, organismos intergubernamentales. Este esfuerzo coordinado; no obstante, también padece de limitaciones, lo cual demuestra la fragilidad de la arquitectura actual del sistema internacional.

Si bien es cierto que los países europeos ya cambiaron sus posturas iniciales y ahora han reforzado su colaboración con los países más afectados por la crisis sanitaria, esa reacción inicial dio una oportunidad única para que China asumiera un rol de liderazgo en la respuesta global contra la pandemia, primero a través de la dotación de paquetes de provisiones médicas como donación a decenas de países afectados por ella, al intercambiar experiencia en la gestión médica de esta, a través de cooperación técnica y, también, mediante un incremento importante en sus contribuciones financieras a la OMS para reducir el impacto de la cancelación de los fondos estadounidenses. Finalmente, se ha desarrollado una especie de diplomacia de vacunas, en las que no solo China ha tenido un rol clave al liderar la vacunación de muchos países en desarrollo, sino también de actores como Rusia con su vacuna Sputnik V.

Entre las múltiples formas que Kissinger (2014) plantea que un orden mundial puede transitar en función de los nuevos balances de poder, una clave es que la potencia emergente asuma el liderazgo sin cambiar la arquitectura del sistema internacional heredado, este escenario es al que, sobre todo potencias regionales como Alemania y Francia parecieran aspirar. En alguna medida el discurso de las autoridades chinas pareciera secundar este punto, así, principalmente evidente en el sistema de comercio mundial, donde China se ha presentado como defensora del sistema actual. De hecho, este país ha venido asumiendo mayores posiciones de liderazgo dentro de las instituciones internacionales como la Unión Internacional de Telecomunicaciones, Departamento de la ONU para asuntos económicos y sociales, Organización para la Alimentación y Agricultura (FAO en inglés), Organización de Aviación Civil Internacional, además de un rol más activo en el Consejo de Derechos Humanos de la ONU (H. Brands, 2020).

Sin embargo, también crece una visión más pesimista que considera a China como una potencia revisionista del statu quo, en especial en lo que se refiere a valores occidentales sobre democracia y los derechos humanos. No puede olvidarse que el sistema actual fue creado por las potencias occidentales que representaban una visión inspirada en el liberalismo político. Su más activa participación y contribución, sin duda, se traduce en una mayor influencia, lo cual genera opiniones encontradas. La visión política liberal occidental no es compartida por igual en China (y en otros centros de poder) y ha quedado 
patente con el caso de sus acciones ante las minorías religiosas y las protestas prodemocráticas en Hong Kong.

En otros ámbitos como en el mar del sur de China (MSC) y el área fronteriza con India también ha quedado manifiesto un nivel de conflictividad creciente producto de un accionar militar más activo, lo cual evidencia el comportamiento de China no solo como un poder blando, sino ya haciendo uso de los instrumentos y medios del poder duro. Esto último ha generado llamados para crear coaliciones entre potencias regionales para "llenar" el vacío generado por la inicial retirada estadounidense y, en contraposición, a la percepción de que China asume un liderazgo revisionista en detrimento de los ideales e intereses de occidente (The Economist, 2020b).

Entonces, ¿está el COVID-19 potenciando la cooperación o el conflicto en el sistema? Según las tendencias ya discutidas la situación de crisis actual inicialmente incrementó el potencial de conflicto en función de la respuesta estatal ante una amenaza percibida como existencial. Al mismo tiempo, al crear una nueva arena en la relación conflictiva entre las dos principales potencias. De forma simultánea, la crisis sanitaria ha desencadenado un gran esfuerzo de colaboración y cooperación, primero estatal, alrededor del posicionamiento de China, y, posteriormente, de actores no estatales como organismos internacionales, tanto para la atención sanitaria como de la crisis económica que ha desencadenado. También, de redes de investigación científica que han permitido el acceso a miles de datos que están facilitando el estudio del virus, los tratamientos, las estrategias de contención y el desarrollo de las vacunas (Apuzzo, 2020).

Esta dinámica de conflicto y cooperación ha quedado patente en cuanto a la distribución de las vacunas, la eficiencia y eficacia del sistema internacional multilateral ha quedado entredicho. El mecanismo COVAX fue incapaz de frenar el voraz apetito de vacunas de los países más ricos, en detrimento de los países más pobres, la brecha en el proceso de vacunación, sin duda, está afectando los esfuerzos nacionales de contención y reducción en el ritmo de avance de la pandemia; así ha quedado patente con el nuevo aumento de casos en países con altas tasas de vacunación como el Reino Unido, la grave situación que atravesaron, de forma previa, India e Indonesia dejó millones de muertos y sistemas de salud colapsados. 


\section{¿Más o menos Estado ante la pandemia? El rol del Estado y otros actores internacionales}

Como se mencionaba en la sección anterior, desde la visión más tradicional de las relaciones internacionales, el Estado es el principal y más preponderante actor en el sistema internacional. No obstante, producto de la globalización y la institucionalidad del sistema, nuevos actores autónomos al Estado han ganado relevancia al tiempo que este ha perdido capacidad de influir de forma efectiva. Actores como grandes corporaciones, movimientos de la sociedad civil, organismos internacionales, redes organizadas transnacionales (crimen organizado, organizaciones terroristas, redes de piratas informáticos, etc.) han ganado preponderancia en el sistema actual, usualmente en detrimento del Estado. Esto ha sido punto recurrente de discusión respecto de las transformaciones que está sufriendo el orden internacional (Keohane, 1989; Murillo Zamora, 2018; Nye \& Keohane, 1971). Tras lo analizado surge la pregunta de si ¿la pandemia está reforzando o no el rol tradicional del Estado? y, en consecuencia, ¿qué pasará con los otros actores del sistema?

Una de las principales características de la respuesta estatal a la actual pandemia ha sido la adopción de medidas extraordinarias en función de, primero, procurar contener la expansión de la pandemia (con restricciones de viajes desde y hacia zonas o países con alta circulación del virus), segundo, la adopción de medidas extraordinarias para disminuir el ritmo de la transmisión en el nivel comunitario en detrimento de la economía y la libre movilidad interna, así como la adopción de medidas para abastecerse de los insumos médicos necesarios para la atención de la pandemia inclusive en perjuicio de socios tradicionales y las normas de comercio mundial. Esta rápida expansión del accionar estatal (con altibajos en distintos países y regiones) ha permitido al Estado retomar espacios cedidos a los otros actores sistémicos en función de la situación de emergencia.

Es decir, ante la crisis actual la respuesta ha sido más Estado, lo cual es común en otros momentos de la historia, como la crisis financiera de 2008, la de 1929, inclusive la respuesta ante la gripe española entre 1919-1920. Así, cabe entonces cuestionarse qué tan duradero será este efecto.

Es importante recordar la misma naturaleza de la amenaza, que es de carácter transnacional y no tradicional. Este tipo de situaciones escapan de la capacidad del Estado para hacerles frente de forma efectiva, sin cooperación internacional, 
pero sobre todo, en este caso particular y en el contexto de interdependencia compleja actual, también requiere de un importante rol de los otros actores.

El Estado presenta importantes limitaciones para afrontarla, primero por la incapacidad de frenar su expansión, segundo por el alto impacto económico que han tenido las medidas de cuarentena, y la gran necesidad de acceder a los mercados internacionales, ya sea para abastecerse de productos esenciales, como recursos financieros frescos, para poder reactivar la economía. Entre ellos, el aparato institucional estatal e internacional no fue construido en función de este tipo de amenazas, si bien existen instituciones encargadas de monitorearlas, es claro que no tenían las condiciones necesarias para frenar, de forma exitosa esta pandemia. Inclusive, la creciente conflictividad entre China y Estados Unidos pudieron ser un factor facilitador para que el virus se propagara, sobre todo si se compara con los casos de SARS y H5N1 que en el pasado fueron afrontados con una mayor cooperación entre las dos potencias (Haenle, 2020).

Esto ha hecho evidente que el sistema contemporáneo, basado en la globalización e interdependencia, requiere de medidas conjuntas para afrentar amenazas transnacionales. El accionar estatal no ha sido capaz de frenarla, se ha requerido del trabajo de coordinación con otros actores como ya se mencionaba en la sección anterior, y sobre todo, se requerirá mucho trabajo coordinado con organismos multilaterales para disminuir el riesgo de una segunda ola, distribuir mejor los insumos médicos, principalmente en apoyo a países en desarrollo, y a lo interno del Estado el rol de actores de la sociedad civil, gobiernos locales, entre otros, será clave para controlar nuevos brotes, asegurar una reactivación económica con cierto grado de seguridad y atender a las poblaciones más vulnerables económicamente.

En cuanto a la gobernanza global, el COVID-19 aceleró la retirada de Estados Unidos de su liderazgo global, su mala gestión interna de la pandemia, la salida de la OMS y el creciente intercambio de acusaciones con China, parece solo contribuir a una transición que se antojaba de décadas pero que, inicialmente, con la administración Trump y la actual crisis ha dejado claro a los demás actores que ha llegado la hora de asumir ese espacio vacío. No obstante, ese espacio vacío será muy poco probable que lo llenen actores no estatales; sin embargo, dependiendo del balance entre China, Estados Unidos y otras potencias de alcance medio, y su visión respecto de la institucionalidad actual, los espacios para los actores no estatales podrían verse muy afectados. 


\section{El balance de poder y el crecimiento de los poderes intermedios}

Las secciones anteriores han planteado que la crisis producto de la pandemia ha venido a acelerar el proceso de transformación del orden internacional. Esto, primero, desde la perspectiva del principio de ordenación al tomar en cuenta la institucionalización del sistema y su grado de interdependencia, que deriva en dinámicas de cooperación y conflicto. Segundo, desde la perspectiva de las unidades, donde se aprecia un esfuerzo inicial del Estado, que deriva en un mayor posicionamiento e inclusive la recuperación de espacios en detrimento de los otros actores del sistema, pero con una progresiva regresión de los actores no estales. Aunque, la naturaleza misma de la nueva amenaza y la transición en el balance de poder genera más incertidumbre respecto de la gobernanza global y los posibles escenarios futuros.

Aquí, entonces, primero, se debe repasar una característica fundamental de la estructura internacional, que se relaciona con la distribución de las capacidades entre las unidades; en este sentido, es clave recordar que el poder originalmente definido como los recursos duros (ejército y poder económico) han perdido eficacia, de esta manera, desarrollos conceptuales como el poder blando y el poder inteligente son claras muestras de lo difuso que resulta, en el sistema actual, determinar cuánto poder o capacidades tienen los actores (Kissinger, 2014; Murillo Zamora, 2018; Nye Jr, 2009; Waltz, 1988).

Parece defendible que los Estados Unidos continúan siendo la mayor potencia militar del orbe y lo seguirá siendo durante los próximos años, su economía también seguirá siendo uno de los principales mercados de exportación mundial, así como sus industrias y poder financiero son grandes recursos para tener en cuenta. En el mediano y largo plazo todo parece indicar que se está frente a las puertas del siglo de China, lo cual no necesariamente se traduce en un cambio internacional profundo, como ya se señaló en secciones anteriores. Aunque, sí muy probablemente, una revisión de los principios en los que se sustenta el orden actual para acomodar una visión más balanceada en contraposición de la occidental.

Entonces, al tener claro que la situación actual acelera las tendencias previas, ¿cabe preguntarse hasta qué punto la actual crisis podría alterar las relaciones entre las grandes potencias? Recordando que, desde la administración de Trump y que, en un grado menos intenso, continúa en la de Biden, la relación de Estados Unidos con China se ha tornado más conflictiva, en particular, producto de la guerra comercial y las disputas por soberanía sobre el MSC. 
Aquí también cabe rescatar que los cambios en la política exterior de China y la rápida expansión de su área de influencia producto, en gran medida de su proyecto de la Nueva Ruta de la Seda, han tenido mucho que ver en esa mayor beligerancia.

Retomando la pregunta anterior, es evidente que la pandemia se ha convertido en un nuevo campo de beligerancia entre las dos potencias, esto si bien no necesariamente se traducirá en una escalada que involucre elementos militares o sanciones económicas, sí se ha tornado en un conflicto por la narrativa sobre la naturaleza del virus y su gestión. Sin embargo, dicha narrativa ha despertado la iniciativa de ciertas potencias regionales por crearse un espacio para, de alguna forma, generar contrapeso a China. Este ha sido el caso de Australia, con su llamado a crear una comisión de investigación internacional sobre el origen y gestión del virus en China. Así mismo, la acción de este país junto a Japón y Estados Unidos para frenar la beligerancia de China en el MSC y, finalmente, con la ya comentada creación del AUKUS.

En el caso de Europa si bien la pandemia no solo ha derivado en una crisis sanitaria y económica sino también de su unidad a lo interno de la Unión Europea (UE), misma que tanto el Brexit como la gestión de la crisis de la deuda había dejado ya patente. En cambio, lo que a todas luces se pronosticaba como una nueva crisis con muy posibles efectos desintegradores pareciera estar transformándose, esto producto del acuerdo franco-alemán de promover la creación de un gran fondo europeo de recuperación con claras ventajas para los países más afectados y, en los acuerdos alcanzados en la UE, enfocándose en la recuperación con medidas sin precedentes de apoyo económico para la reactivación. Estos esfuerzos son un paso importante en la reafirmación de Europa como actor, empero, aún faltan mayores esfuerzos en materia militar, en lo cual Francia ha insistido en la necesidad de más integración militar en Europa, con una mayor autonomía del apoyo y tecnología de EE. UU. Esto podría oxigenar su capacidad de liderar "el mundo libre".

Lo anterior podría implicar que la UE sería la plataforma para reunir a los actores que aun respaldan los principios del orden liberal occidental para balancear a China, ante un posible esfuerzo por expandir e influir su "visión revisionista" y sus principios como potencia reformista. Este escenario; a la postre, pasa por la negociación con los países "frugales" como Holanda, Austria, Suecia y Dinamarca; además, es importante no olvidar que dentro de la UE países como Polonia y Hungría presentan una visión menos liberal al bloque, lo cual está generando más roces a lo interno. De momento, la apuesta por una Europa unida para liderar la visión liberal occidental pareciera más limitada al rol de sus principales líderes como Alemania y Francia. 
Los casos de India, Rusia y Brasil muestran varios escenarios posibles. En primer lugar, la creciente conflictividad de India con China podría generar una mayor inclinación de la inicial en unirse en coalición a países como Australia y Japón, inclusive India, en sí mismo, tiene un gran potencial de crecimiento futuro para, por cuenta propia, balancear la influencia China, sin embargo, aún arrastra grandes retos que ahora reforzados por los efectos de la pandemia podrían retrasar más sus aspiraciones. Pareciera que India es un socio natural para Estados Unidos y Europa en su búsqueda de balances y contrapesos con China.

En cuanto al caso de Rusia, este se ha mantenido más cercano a China producto de la convergencia en aspectos de su visión de mundo como de intereses conjuntos. Son socios en múltiples iniciativas, pero sus relaciones con Europa también son clave para su economía. Rusia sigue siendo una importante potencia militar, lo cual ha sabido aprovechar para ganar influencia en varios conflictos como en Siria y Libia, lo cual le coloca como un actor clave a considerar por parte del resto de potencias. No obstante, su estructura económica, basada grandemente en energía fósil y el gran impacto de las sanciones de occidente, más la pandemia, podrían dejarle muy vulnerable. Además, la mayor presencia e importancia de China en Asia central, zona de influencia tradicional rusa, podría derivar en escenarios de competencia y conflicto entre estos dos poderes.

Brasil en América Latina se ha visto muy afectado por las crisis económicas, políticas y ahora de sanidad producto del COVID-19, a diferencia de hace poco más de una década que se percibía como una eventual potencia a tomar en cuenta, las condiciones parecieran no estar en su favor como para jugar un peso preponderante en el nivel mundial, su dependencia de productos primarios también le hace muy susceptible de caer junto a otros países de la región en la órbita de influencia de China, con la única excepción de México y los países centroamericanos.

Brasil y México, que son llamados a ser las potencias regionales, están mostrando mucha fragilidad y vulnerabilidad ante la pandemia, en gran medida, producto de su mala gestión de la crisis, lo cual, sin duda, ha agravado los efectos negativos. Además, sus falencias en materia de sanidad y grandes brechas sociales también han favorecido la rápida expansión del virus. Es decir, tanto sus limitaciones estructurales internas como la mala gestión de sus líderes han creado las condiciones para que la pandemia genere impactos sumamente profundos.

En este sentido, como se mencionó antes, los países de América Latina pueden ser divididos entre dos bloques. En el primero están los países más dependientes de materias primas como Colombia, Venezuela, Brasil, Chile y Argentina, 
lo cual crea una estrecha relación entre el crecimiento y la demanda global, pero, sobre todo de China, con el éxito de sus economías. Y en un segundo plano, los países más dependientes de sus relaciones comerciales con Estados Unidos producto de la inversión extranjera directa que funciona en sus territorios, como lo son México y los países centroamericanos. En el primer grupo, las condiciones globales de la crisis primero generaron una contracción de la demanda global, sin embargo, con la llegada de las vacunas y el levantamiento de las principales restricciones contra la pandemia, llevadas a cabo a lo largo de 2021, se ha propiciado una recuperación de la demanda en el sector materias primas y energía, con una importante alza en sus precios, beneficiando a estos países. Esto podría influenciarlos para estrechar más sus lazos con China, fortaleciendo así su dominio en la región.

En el caso de los otros países, más dependientes de Estados Unidos, la situación actual es crítica por un doble sentido, primero por la contracción económica en casa, producto de las cuarentenas, pero también del parón económico de Estados Unidos hasta el primer semestre de 2021, esto fue crítico en la situación económica de la región, en especial para los países del norte de Centroamérica, al exponer, aún más, su fragilidad económica y social, con un consecuente aumento de la migración irregular con destino a Estados Unidos. En términos de las zonas de influencia, esto también podría ser aprovechado por China para fortalecer su presencia en una región donde aún países como Honduras, Nicaragua y Guatemala mantienen relaciones con Taiwán.

En cuanto a África, este continente ha sido una de las principales apuestas de China con su proyecto de la Nueva Ruta de la Seda lo cual le ha permitido extender su influencia en casi todos los países del continente, lo cual se suma al hecho de que las preocupaciones por los derechos humanos y la democracia no entran en la agenda de China, esto facilita su relación con los regímenes más autoritarios del continente. Un escenario muy plausible sería el que este continente, en su gran mayoría, se convertiría en área de influencia China, pero, muy posiblemente, bajo la competencia de las otras potencias, aunque con menor éxito.

\section{El sistema internacional pos COVID-19 y sus efectos en Centroamérica}

Como se mencionó al inicio de este artículo, el sistema internacional pareciera apuntar hacia tres grandes tendencias en el mundo pos COVID-19: i) una mayor fragmentación y bifurcación; ii) la ausencia de un administrador del sistema internacional con las implicaciones que ello conlleva; y iii) un mayor 
protagonismo de los denominados poderes intermedios. Aunado a estos elementos de carácter estructural igualmente se identifican efectos más directos e inmediatos como son la securitización de la agenda covid-19, la profundización de la interdependencia del sistema, producto de la naturaleza transnacional de la COVID-19 e, igualmente, el incremento de la participación de poderes intermedios, pero también de actores no estatales, sobre todo en el contexto de la producción de la vacuna, su aplicación y distribución.

En la sección anterior se evidencia que la crisis de la pandemia en Centroamérica se sumó a los problemas que la región ya venía arrastrando, producto de su mayor vulnerabilidad a la crisis climática, una situación de seguridad crítica, consecuencia del proceder de actores no estatales como las pandillas y el narcotráfico internacional y, su penetración en las ya de por sí debilitadas instituciones estatales; economías que arrastran importantes deficiencias como una alta informalidad y baja capacidad de generación de empleos. A estos aspectos se le debe sumar el auge de un mayor autoritarismo de las élites políticas y el debilitamiento de las instituciones democráticas, en especial el caso de Nicaragua, El Salvador y, con menor intensidad, Honduras y Guatemala.

El orden liberal internacional ha sido construido sobre tres principales mecanismos que, en mucho, provienen del pensamiento del filósofo alemán Immanuel Kant: instituciones internacionales, democracias constitucionales e interdependencia económica, todas los cuales son necesarias para mantener la paz internacional. Lo anterior ha generado que el sistema actual esté centrado sobre tres ideas centrales: la existencia de un sistema abierto para el comercio y los negocios, el desarrollo de un sistema internacional multilateral basado en reglas $\mathrm{y}$, finalmente, los modelos democráticos liberales.

En el contexto centroamericano y en el marco del bicentenario que debía haber consolidado los ideales de Kant, parece estarse produciendo lo contrario. En la esfera económica, el incremento del proteccionismo en la región, con algunas excepciones, a pesar de los acuerdos de libre comercio y la adherencia a las reglas de la Organización Mundial de Comercio, es cada día más común. Las restricciones migratorias en materia laboral, el casi nulo avance de la unión aduanera, la lentitud del tránsito de mercancías en la región, son todas manifestaciones del nacionalismo económico.

En la arena política los déficits democráticos se están expandiendo rápidamente en países que se suponen democráticos, así el aumento de los populismos es notorio en los casos de Nicaragua y El Salvador. En la esfera institucional, el impacto es también visible en el debilitamiento de las instituciones democráticas, aquí ningún país de la región se escapa, pero claro, los grados son 
distintos, pues en Nicaragua, El Salvador, Honduras y Guatemala es un problema mayúsculo.

Ante esta situación, entonces ¿qué implican estos cambios sistémicos para la región centroamericana? En primer lugar, la región ha adquirido mayor preponderancia como zona de influencia. La administración Biden ha lanzado importantes señales de que va a intervenir con mayor intensidad en ella. Existe un importante nivel de coincidencia en que con la administración del presidente Biden, Centroamérica tendrá una cercanía mayor a la Casa Blanca; sin embargo, ello no significa que pase a ser tema central de la política exterior de los Estados Unidos. Este refrescamiento de las relaciones entre Estados Unidos y la región parece estar centrado en tres grandes temas: primero, la lucha contra el cambio climático, asunto que en la agenda de Biden es prioritario en la política exterior y que, en la región ha adquirido también gran preponderancia, sobre todo en cuanto a la adaptación a los efectos negativos del cambio climático. Segundo, el tema de la migración y la agenda de seguridad que se interconectan, este tema es quizá, de entrada el cual, , el actual gobierno ha iniciado más rápido el proceso de reinicio, producto de la eliminación de varias órdenes ejecutivas aprobadas por Trump. Tercero, el reto del fortalecimiento de la democracia en la región, que se encuentra claramente en franco retroceso.

El desafío de la administración Biden-Harris será mayor en este tema, ya que enfrenta una región donde los principios y valores democráticos han decaído de forma continua en el último lustro. Según el Global Democracy Index 2020 (2021) de la reconocida revista The Economist, solo un país de la región es una democracia completa, el resto de los países de la región son considerados democracias "defectuosas" o regímenes "híbridos" e, incluso, autocráticos. En el contexto del bicentenario la realidad descrita antes es preocupante, ya que la democracia y el orden liberal occidental requieren de la legalidad y legitimidad. Precisamente, autores como Levitsky y Ziblatt (2018) han planteado que la decadencia de las democracias se está dando producto del rechazo o endeble aceptación de las reglas democráticas, en especial la legitimidad de los adversarios políticos, la aceptación o fomento de la violencia con motivaciones políticas y la propensión a restringir las libertades civiles de los partidos o grupos opositores, incluidos la prensa. Por otra parte, para el autor Mounk (2018) la situación actual, en muchas sociedades en desarrollo, es de convulsión del pueblo contra la democracia, por cuanto se ha considerado la democracia liberal como la única forma posible de organización de la sociedad, sin valorarse otras como los liberalismos no democráticos e incluso las democracias iliberales. 
Entre algunas de las medidas que desde Estados Unidos se están trabajando está, atender las causas que generan la expulsión de población del triángulo norte, para ello ha comprometido un paquete de cooperación de 4 mil millones de dólares; sin embargo, este paquete ha prometido no se dará directamente a los gobiernos, si no que se buscará trabajar con otro tipo de actores y, ante todo, se demandarán mejoras en aspectos como corrupción, transparencia y Estado de derecho.

Además, se ha mostrado más dispuesto en implementar sanciones más fuertes contra el régimen de Ortega, lo cual se prevé aumente, a corto plazo, con el empeoramiento de las condiciones políticas de cara a la farsa electoral de noviembre de 2021 y sus consecuencias a posteriori. Este tipo de sanciones a funcionarios públicos también han sido implementadas en Guatemala, Honduras y El Salvador.

Otro importante anuncio es la iniciativa del B3W (Build Back Better World por sus siglas en Inglés), el cual es un programa que busca competir con el proyecto de la Nueva Ruta de la Seda de China. Este programa tendrá un mayor alcance en el nivel continental, buscando conectar las américas a través de una importante inversión en infraestructuras críticas, que fomenten una mayor integración de las economías, en especial en carreteras, trenes, puertos y banda ancha de internet.

Esta iniciativa del B3W será clave para apoyar los esfuerzos que desde el sector empresarial se vienen realizando para reubicar inversiones y capacidad operativa en regiones más cercanas a los principales mercados (nearshoring), América Latina, y, en especial, la zona más cercana a la influencia estadounidense, está recibiendo una mayor inversión extranjera directa producto de dicha relocalización.

Este proceso de bifurcación sistemático se presenta también en la región, el nuevo autoritarismo en varios de los países, principalmente del norte, pareciera acercarlos más a la visión revisionista y modelo chino, mientras que países como Costa Rica, Panamá y República Dominicana mantienen una mayor cercanía con la visión del modelo occidental liberal. De hecho, estos últimos tres, recientemente, han lanzado una "Alianza para el fortalecimiento de la institucionalidad democrática", la cual busca promover el crecimiento económico en el marco de la democracia, los derechos humanos y los objetivos de desarrollo sostenible. Lo interesante de esta iniciativa es que busca levantar una especie de cortafuegos contra el mayor autoritarismo del resto de socios del Sistema de la Integración Centroamericana (SICA). A corto plazo, esto tendrá retos 
importantes para la integración y sus instituciones, donde la fragmentación ya planteada en el nivel sistémico, también se presenta en el nivel regional.

Si bien, no necesariamente, se prevé una confrontación entre los países de la región, las condiciones actuales parecen alentar una mayor fragmentación dentro del SICA y una menor capacidad de funcionamiento de la institucionalidad de la integración, esto, sin duda, queda así patente con la incapacidad de la región de nombrar a un nuevo Secretario General, puesto que está vacante desde finales de junio.

Estas dos situaciones: una mayor preponderancia de la región, en particular, en la agenda de Estados Unidos y la bifurcación interna, producto de un nuevo auge del autoritarismo en varios de los países, prevé que la región tendrá un escenario complejo para lidiar con el contexto de mayor cooperación y conflicto entre las potencias, tanto globales como regionales. Además, su fragilidad la hace más vulnerable a la influencia no solo de estos actores sino también de los actores no estatales, en especial, de redes transnacionales de crimen. La región en el marco del bicentenario de su independencia arrastra aún importantes deudas no solo sociales y económicas, sino ahora también ambientales que incrementan su vulnerabilidad.

La COVID-19 ha reforzado aún más esta crisis, poniendo de manifiesto la fragilidad económica y la debilidad de los sistemas de salud de la región. Esta crisis de salud y económica ha derivado también en una gran fragilidad social, por cuanto las capacidades de ascenso social, prácticamente se han transformado en estructuras de rápidos declives sociales. La aspiración general de mejorar o al menos mantener, las condiciones actuales de vida, han sido cercenadas para una gran mayoría. Grandes segmentos de la población solo están enfocados en su subsistencia; cuando se padecen estas situaciones de ausencia de entregables desde la institucionalidad democrática del Estado, se incrementan las condiciones que derivan en rápidos estallidos sociales, con componentes de violencia colectiva (Norris \& Inglehart, 2019) .

La región ya conoce las consecuencias de convertirse en un escenario de conflicto bélico, en el marco de un contexto de guerra fría, después de graves retrocesos y pérdidas fue capaz de construir un acuerdo de mínimos para atender los conflictos e iniciar la reconstrucción. Si se desea evitar volver a ser un escenario de confrontación en una segunda guerra fría, la región requiere, de manera urgente, atender la fragmentación interna y las brechas que arrastra desde su independencia. 


\section{Referencias bibliográficas}

Apuzzo, M. K., David. (2020, 14 April 2020). Covid-19 Changed How the World Does Science, Together. The New York Times. Retrieved from https://www. nytimes.com/2020/04/01/world/europe/coronavirus-science-research-cooperation.html

Brands, H. (2020). China's global influence operation goes way beyond the WHO. The Japan Times. Retrieved from https://www.japantimes.co.jp/opinion/2020/04/01/commentary/world-commentary/ chinas-global-influence-operation-goes-way-beyond/

Brands, H. L. G., John. (2021). The New Cold War. Foreign affairs, November/December. Retrieved from https:/www.foreignaffairs.com/articles/ united-states/2021-10-19/new-cold-war

Dupont, A. (2020). New Cold War: de-risking the US-China conflict. Retrieved from https://www.hinrichfoundation.com

Fukuyama, F. (1989). The End of History? The National Interest(16), 3-18. Retrieved from www.jstor.org/stable/24027184

Haenle, P. T., Lucas. (2020). U. S.-China Cooperation on Coronavirus Hampered by Propaganda War. Retrieved from https://carnegieendowment. org/2020/03/24/u.s.-china-cooperation-on-coronavirus-hampered-by-propaganda-war-pub-81347

Keohane, R. O. (1989). International institutions and state power: Essays in international relations theory: Westview Pr.

Kissinger, H. (2014). World order: Penguin Books.

Levitsky, S., \& Ziblatt, D. (2018). How democracies die: Broadway Books.

Mounk, Y. (2018). The people vs. democracy: Harvard University Press.

Murillo Zamora, C. (2018). Reconceptualización de Relaciones Internacionales en un mundo transformado. Escuela de Relaciones Internacionales, Universidad Nacional. https://repositorio.una.ac.cr/bitstream/handle/11056/14580/ publication-ilovepdf-compressed.pdf?sequence $=1 \&$ isAllowed $=\mathrm{y}$

Norris, P., \& Inglehart, R. (2019). Cultural backlash: Trump, Brexit, and authoritarian populism: Cambridge University Press.

Nye Jr., J. S. (2009). Get smart: Combining hard and soft power. Foreign affairs, 160-163. 
Nye, J. S., \& Keohane, R. O. (1971). Transnational Relations and World Politics: An Introduction. International Organization, 25(3), 329-349. doi:10.1017/ S0020818300026187

Rosenau, J. (2007). Globalization and governance: bleak prospects for sustainability. Internationale Politik und Gesellschaft,().

The Economist. (2020a, May 9th). The new scold war: The pandemic is driving America and China further apart. The Economist. Retrieved from https:// www.economist.com

The Economist. (2020b, June 18th). The new world disorder. The Economist. Retrieved from https://www.economist.com/leaders/2020/06/18/ the-new-world-disorder

Unit, T. E. I. (2021). Democracy Index 2020. In sickness and in health? Retrieved from www.ieu.com

Waltz, K. N. (1988). Teoría de la Política Internacional: Grupo Editor Latinoamericano.

Wintour, P. (2020, 22 June 2020). US v China: is this the start of a new cold war? The Guardian. Retrieved from https://www.theguardian.com/world/2020/ jun/22/us-v-china-is-this-the-start-of-a-new-cold-war 
